\title{
La alianza entre pehuenches e hispano-criollos mendocinos en el marco del conflicto contra los huilliches-ranqueles, a fines del siglo XVIII
}

The alliance between Pehuenches and Hispanic-creoles from Mendoza in the context of the conflict with the Huilliches-Ranqueles, at the end of the eighteenth century

\section{Luciana Fernández}

\section{(2) OpenEdition \\ Journals}

\section{Electronic version}

URL: http://journals.openedition.org/corpusarchivos/3458

DOI: 10.4000/corpusarchivos.3458

ISSN: 1853-8037

\section{Publisher}

Diego Escolar

\section{Electronic reference}

Luciana Fernández, «La alianza entre pehuenches e hispano-criollos mendocinos en el marco del conflicto contra los huilliches-ranqueles, a fines del siglo XVIII », Corpus [En línea], Vol. 10, №. 1 | 2020, Publicado el 28 junio 2020, consultado el 02 julio 2020. URL : http://journals.openedition.org/ corpusarchivos/3458; DOI : https://doi.org/10.4000/corpusarchivos.3458

This text was automatically generated on 2 July 2020. 


\section{La alianza entre pehuenches e hispano-criollos mendocinos en el marco del conflicto contra los huilliches-ranqueles, a fines del siglo XVIII}

The alliance between Pehuenches and Hispanic-creoles from Mendoza in the context of the conflict with the Huilliches-Ranqueles, at the end of the eighteenth century

Luciana Fernández

\section{Descripción del documento}

La fuente que presentamos en esta ocasión se encuentra resguardada en el Archivo General de la Nación de Argentina (en adelante AGN), sala IX, División Colonia, Sección Gobierno, Legajo 24.2.2, Guerra y Marina (1792) y se corresponde con el Expediente 19, el cual contiene aproximadamente 8 fojas escritas ${ }^{2}$ en anverso y reverso, sin numerar, entre las que encontramos oficios originales y copias de oficios. ${ }^{3}$ Estos están escritos con un trazo bien marcado y con una letra clara por lo que no se presentaron importantes inconvenientes a la hora de la lectura o transcripción. Hay una suerte de carátula en la que se puede advertir varias grafías con diferentes colores de tinta. La grafía en tinta negra es similar a la presente en las fojas del documento por lo que podemos especular que es de la época y elaborada por algún funcionario colonial. Entre otros elementos, especifica el número de Legajo (48), el lugar (Córdoba) y el año (1792), así como el siguiente título: "El Intendente de Cordova, dando parte de la salida de una partida de la Guarnición de Mendoza al campo de los Enemigos, solicita la aprobación de los gastos con dho motivo". 
Las otras tres grafías presentes en la carátula seguramente deben haber pertenecido a diferentes archiveros. La tinta de color rojo vivo indica un número de Legajo que no coincide con el especificado por la otra grafía y las siglas "Gx Mar." La grafía con tinta bordó especifica un número que tampoco coincide con los anteriores, pero sí con la información contenida en una etiqueta que se encuentra tachada con color rojo y que dice: “Año 1922. C.X A. 5 Leg. 5 N¹2”. Esta etiqueta, así como otra presente en la carátula, son propias de la rotulación hecha por los archiveros del AGN. La última etiqueta en cuestión dice “Guerra y Marina. Leg. 18. Exp. 19.”, correspondiéndose entonces con la información detallada en los catálogos del AGN. Sobre el margen izquierdo se encuentra el sello del Archivo General de la Nación Argentina.

Los oficios están fechados entre diciembre de 1791 y marzo de 1792 y dan cuenta del enfrentamiento entre los pehuenches ${ }^{4} \mathrm{y}$ los huilliches-ranqueles ${ }^{5}$ así como del auxilio mendocino a sus "indios amigos". ${ }^{6}$ Uno de los temas recurrentes en esta documentación, y en general en la política colonial, es la preocupación de los hispanocriollos en cuanto a cómo la conflictividad entre parcialidades indígenas los afectaría directa e indirectamente, acrecentando sus gastos y obligándolos a replantearse su política fronteriza. En relación con esto, la documentación es muy rica dado que incluye los oficios -o copias de oficios- y las respectivas contestaciones a ellos, de forma que podemos identificar ciertas polifonías en la comunicación entre diferentes actores de la frontera de Mendoza: el comandante del fuerte de San Carlos (don Juan Morel), comandante de frontera de Mendoza (don José Francisco de Amigorena), el gobernador intendente de Córdoba del Tucumán (don Rafael de Sobremonte) y el mismísimo virrey (don Nicolás de Arredondo), sin pasar por alto los documentos elaborados por los ministros de Real Hacienda (por ejemplo, don José Antonio Palacio). No obstante, hasta el momento nos fue imposible acceder a algunos oficios originales por lo que ello nos ha creado un interrogante al momento de abordar y analizar la documentación: ¿Hasta qué punto lo transmitido, transcripto o parafraseado en algunas copias de oficios se corresponde con el mensaje original? Por ejemplo, la primera foja es una copia de la contestación del virrey Arredondo (fechada el 24 de diciembre de 1791) al oficio del 19 de diciembre de 1791 del marqués de Sobremonte, documento en el que el gobernador manifiesta transmitir lo que Amigorena le informó. A pesar de ello, al no estar presente en el expediente el oficio elaborado por Sobremonte y dirigido al virrey, tampoco el oficio de Amigorena dirigido a Sobremonte, nos es muy dificultoso determinar cuáles serían las partes parafraseadas del mensaje de Amigorena y cuáles son expresiones originales de los restantes sujetos inmersos en este intercambio de escritos. Asimismo, hay un oficio original del 18 de febrero escrito por Amigorena y con Sobremonte como receptor en el que manifiesta adjuntar una copia de la carta que don Juan Morel le envió el 14 de febrero desde la Villa de San Carlos. Dicha copia no se encuentra inmediatamente citada sino un par de oficios luego, y comienza de la siguiente forma: "El Comandante Ynterino de la Frontera de S ${ }^{\mathrm{n}}$ Carlos $\mathrm{D}{ }^{\mathrm{n}}$ Juan Morel con fha de 14 del corr ${ }^{\text {te }}$. me dize lo sig ${ }^{\text {te.....". }}$

En este caso, lo que está escrito a continuación se encuentra narrado en primera persona y está fechado el 14 de febrero desde la Villa de San Carlos, por lo que suponemos que es una transcripción literal de la carta que Morel le envió a Amigorena. Entonces, en los oficios del Expediente 19 encontramos varios casos de polifonías -en algunos casos bajo la forma del parafraseo, en otras como citas textuales-. Si bien nos es imposible determinar hasta qué punto el emisor está transmitiendo el mensaje 
original de quien le escribió en un inicio - sin ningún tipo de agregado ni sustracción-, no le quita verosimilitud a la documentación en cuestión.

\section{Criterios para la transcripción del documento}

El expediente fue fotografiado en su totalidad con una máquina fotográfica y luego transcripto de acuerdo a la transcripción literal modernizada propuesta por Tanodi (2000), por la cual el texto presente en la fuente permanece fiel al manuscrito y se lo acerca de la forma más accesible al lector.

En líneas generales, se respetó la ortografía original del documento ya que consideramos que esto no acarreará una dificultad en la lectura ni en la comprensión del contenido, ${ }^{8}$ sino que incluso permitirá analizar los rasgos internos y la forma de escritura propia del contexto de elaboración. Mantuvimos todas las mayúsculas presentes en el documento. Algunas se encuentran en los rótulos étnicos (ejemplo: Yndios Pehuenches); otras son usadas para referenciar autoridades (Comandante de Frontera, Cacique) o instituciones coloniales, por lo que están escritas de este modo a lo largo de toda la documentación transcripta. Por último, algunas mayúsculas son usadas, por quien escribió, para destacar algunas palabras o expresiones. Por ejemplo, en un oficio del documento se quiere enfatizar que el cacique pehuenche Currilipi mantuvo una "Viva Guerra" contra los huilliches-ranqueles. Asimismo, mantuvimos las abreviaturas propias de la escritura de época y los signos de puntuación porque consideramos que no impiden la lectura fluida ni la interpretación. No obstante, hemos efectuado algunas modificaciones que consideramos necesarias tales como agregar ' $h$ ' en algunas palabras, reemplazar ' $v$ ' por ' $u$ ' y separar las contracciones de la preposición 'de' con la palabra siguiente. A su vez, hemos modernizado el uso de tildes. En los casos de palabras o frases agregadas en los márgenes por parte del mismo funcionario colonial, en el escrito se contuvo la expresión entre corchetes y se aclaró en nota al pie que se trata de un agregado y en qué margen está presente. Con palabras de identificación dudosa, colocamos a continuación de la versión dada un signo de interrogación entre corchetes. Cuando la palabra está inconclusa, ya sea por manchas que la cubren, roturas del papel, claros dejados en el documento por el funcionario que lo redactó o bien no se puede acceder a la lectura total de la palabra por la encuadernación del documento, esto fue señalado con puntos suspensivos encerrados entre corchetes, y en nota al pie se aclaró a qué factor se debió. En aquellos casos en que esa palabra pudiese ser completada por el transcriptor, se lo hizo de la siguiente forma: claram [ente], y en nota al pie se aclaró a qué elemento se debió. Cuando es imposible entender la palabra o los números, se aclarará a continuación lo siguiente: [ilegible]. Las palabras escritas de manera defectuosa fueron conservadas, pero a continuación se sugirió la forma correcta, por ejemplo: advitrios [sic: arbitrios]. Por último, para señalar una firma, tras la misma se aclaró lo siguiente: [firmado].

\section{Comentario del documento}

Durante el periodo colonial, desde la variable político-administrativa, Mendoza formó parte de Cuyo. Esa jurisdicción fue objeto de disputas entre la Gobernación del Tucumán y la Capitanía General de Chile, por hacerse del derecho de apropiación de grupos indígenas nativos denominados huarpes en concepto de encomienda sin residencia. Este conflicto concluyó con la convalidación real a favor del Reino de Chile. 
Desde Santiago de Chile se procedió a la fundación de las ciudades de Mendoza (1561), San Juan (1562) y San Luis (1594). Desde 1564 Cuyo fue Corregimiento del Reino de Chile y tuvo como capital a Mendoza, hasta que en 1776 fue incorporado al ámbito rioplatense y pasó a depender de la Intendencia de Córdoba del Tucumán. Pero, aún después de la incorporación de Cuyo al nuevo virreinato, Mendoza fue una región bisagra entre el Virreinato del Río de la Plata y la Capitanía General de Chile; y quedó vinculada a Chile en lo comercial, cultural y social (Roulet, 2016).

Sobre la configuración del espacio, Gascón $(2009,2011)$ formula la noción de "espacio imperial" y el fenómeno por el cual regiones periféricas se articulan con él en función de sus necesidades defensivas. Para el caso de Mendoza, la autora establece que a fines del siglo XVI la Corona debió modificar su estrategia defensiva en el Mar del Sur y militarizar la frontera a la altura del río Biobío tras la exitosa campaña del inglés Francis Drake en el estrecho de Magallanes y la rebelión araucana. Entonces, ante las necesidades imperiales de defensa del sur del Virreinato peruano y la sostenida demanda de recursos materiales (principalmente, ganado vacuno y caballar) y humanos (encomiendas huarpes), Mendoza se articuló al espacio imperial -y específicamente con la línea de frontera de Arauco- a partir del tráfico ganadero en sentido este-oeste y la ruta que comunicaba Buenos Aires con Santiago de Chile vía San Luis. De esta forma, a pesar de que la colonia periférica de Mendoza no estaba ubicada en la frontera estrictamente geográfica y militar, devino en una frontera interétnica y adquirió la dinámica de sociedad de frontera, porque allí confluyeron diferentes parcialidades indígenas (puelches, ${ }^{9}$ pampas, ${ }^{10}$ ranqueles, huilliches y pehuenches) y poblaciones españolas e hispano-criollas, con sus similitudes, diferencias e interacciones.

1 A fines del siglo XVII y principios del XVIII se conformaron asociaciones laxas entre diferentes grupos indígenas, para controlar áreas estratégicas o realizar correrías en los territorios ocupados por los hispano-criollos (Durán, 1993-1994). Ante el ataque de algunos de esos grupos nómades (puelches, pehuenches y huilliches) contra las estancias en el valle de Uco y Jaurúa en busca de ganado, debió desarrollarse una defensa del territorio que implicó esporádicas expediciones punitivas y la reducción de tolderías puelches chiquillanes y algunos pampas en el valle de Jaurúa para que actuasen como una franja de amortiguación que contuviese las invasiones de indígenas enemigos (Prieto, 1989). Avanzado el siglo XVIII, las hostilidades indígenas se recrudecieron. En 1769, con la agitación general en el Reino de Chile y su extensión a Cuyo, los pampas y puelches chiquillanes reducidos abandonaron la reducción y atacaron las estancias fronterizas, tras lo cual se dispersaron en territorio indígena (Roulet, 1999-2001). ${ }^{11}$

En dicho contexto, también los pehuenches emprendieron expediciones militares contra Chile, Mendoza, Buenos Aires y contra todo aquel “...que quisiera disputarle el control de los pasos cordilleranos por lo que circulaba el tráfico comercial entre el Valle Central y las pampas" (Villar y Jiménez, 2003, p. 139), como fue el caso de los huillichesranqueles..$^{12}$ Estos, en pos de disputarles el control del acceso a recursos importantes (como el ganado, la sal, entre otros) y/o movidos por el afán de los líderes de concretar sus proyectos políticos y satisfacer sus ansias de prestigio y destaque, se enfrentaron a ellos en incontables ocasiones desempeñando -ambos grupos- expediciones punitivas y de venganza que fueron destructivas para los contendientes.

En 1774 se fundó, en el valle de Uco, el fuerte de San Carlos para proteger la frontera y para terminar con las invasiones indígenas a los asentamientos fronterizos y estancias. Así, se implementó una política de pacificación que se valió del uso de la fuerza, pero 
también de las alianzas, los acuerdos y los parlamentos (León Solís, 1982), la entrega de agasajos, el comercio interétnico y el velar por las relaciones personales entre los sujetos. Todo ello fue puesto en práctica por Amigorena, quien en 1779, 1780, 1783, $1784,{ }^{13} 1787$ y 1789 desarrolló ofensivas militares contra los caciques pehuenches. Durante su expedición al cerro Campanario en 1780, pretendió arremeter contra los toldos del cacique pehuenche Ancanamun pero estaban vacíos. ${ }^{14}$ No obstante, dio muerte a otros caciques, entre ellos, al hermano de Ancanamun, Llinguenquen. León Solís explica que para Ancanamun, la campaña del comandante fue desastrosa:

...pues gran parte de la infraestructura que había sostenido su surgimiento yacía en ruinas, algunos de sus lonkos estaban muertos y su principal capitanejo había sido asesinado; con la gente cautiva, despojado de sus ganados y sus tolderías destruidas, el futuro no se veía nada promisorio, menos todavía cuando en el horizonte se dibujaba la sombra de las turbas maloqueras huilliches que irrumpían desde el sur (León Solís, 2001, p. 80). 151617

Abocándonos a la fuente que presentamos en esta oportunidad, en copia del oficio del virrey Nicolás de Arredondo fechada el 24 de diciembre de 1791, se refiere que el 19 de ese mes llegó el oficio del gobernador intendente Sobremonte desde Córdoba informándole que el comandante Amigorena -desde Mendoza- avisó que el cacique pehuenche Calbullan le solicitó la paz, a lo cual accedió, y detalla que llegó acompañado

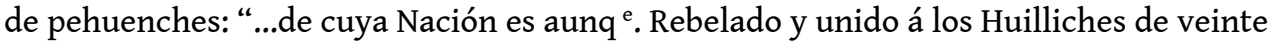
años a esta parte; $y$ de las ventajas $q{ }^{e}$. ofrece la amistad del referido...". ${ }^{18} Y$ que Calbullan prometió: “...engrosar el partido de los Pehuenches, y devilitar el de los Huilliches...". ${ }^{19}$

Estos extractos nos invitan a leer entre líneas, a buscar algún indicio que nos permita encontrar información sobre temas para los cuales esos documentos no fueron necesariamente escritos (Nacuzzi, 2002). De esta forma, nos surgieron interrogantes: Primero, ¿por qué Calbullán se apartó de los pehuenches y se unió a los huilliches? Segundo, ¿qué cambió para que tomara la decisión de volver con los pehuenches? Por último, ¿por qué se consideraba conveniente su amistad?

En cuanto al primer interrogante, el caso de este cacique nos invita a reflexionar sobre el hecho de que cuando uno habla de una parcialidad indígena está haciendo referencia a un colectivo muy amplio de caciques e indiada que no necesariamente tuvieron decisiones, acciones y estrategias unánimes y homogéneas sino, por el contrario, variadas y oscilantes. En relación con ello, tal como indica Roulet (2011), el ser pehuenche, huilliche o ranquel era una opción política que respondía a una coyuntura específica. Las trayectorias de vida de los caciques nos demuestran lo permeable que eran las fronteras étnicas y los cruces y mestizajes que se dieron desde los Llanos de Chile hasta las tolderías de Tandil. ${ }^{20}$ Calbullán es un ejemplo de ello.

De acuerdo a León Solís (2001), en el contexto de la expedición de $1788,{ }^{21}$ el Comandante Esquivel Aldao dijo sobre él: "tenía 2 mujeres guiliches, cuya parentela componía el numero de 60..." (León Solís, 2001, p. 16). A la luz de esta información, podemos suponer que Calbullán pudo haber emigrado hacia tierras huilliches, dejando atrás su adscripción pehuenche, en virtud de que contrajo matrimonio. Lo destacable es que incluso tras pertenecer originariamente a una parcialidad enemiga de los huilliches, con su emigración y generación de vínculos de parentesco pudo haber sido integrado totalmente en el cuerpo social huilliche.

En cuanto al segundo interrogante, la fuente nos brinda una pista que, a la luz de la lectura de la bibliografía especializada, consideramos clave. Respecto a la intención de 
Calbullan se tiene: “...fundada duda de $\mathrm{q}^{\mathrm{e}}$. no le haya movido otro interés a dho Calbullan, $\mathrm{q}^{\mathrm{e}}$. el de estar unido al Partido más pujante...". ${ }^{22}$ Apelando a estas últimas palabras, podríamos especular que posiblemente Calbullan se acercó a los pehuenches y le pidió la paz a Amigorena porque, en el contexto del enfrentamiento contra los huilliches-ranqueles, los pehuenches eran aliados de los hispano-criollos y la balanza se inclinaba a favor de este último bando, habiendo salido victoriosos en múltiples ataques a las tolderías huilliches-ranqueles. Por esa razón, unirse al "Partido más pujante" era lo más conveniente para ese cacique si no quería seguir sufriendo los avatares de la guerra en sus tolderías. Además, al pactar la paz con los mendocinos pasaba a ser "indio amigo" y, como tal, quedaba protegido por esa alianza. Colabora en fortalecer esta idea que esbozamos el hecho de que luego de la expedición de 1788 se recuperaron animales robados, pero también se cautivaron 340 huilliches a los cuales “...se agregó voluntariamente el séquito del lonko Calbuyllan" (León Solís, 2001, p. 195). Esto nos lleva a plantearnos: ¿acaso ya en 1788 Calbullan advertía que esta derrota huilliche agravaría el panorama y desencadenaría una seguidilla de enfrentamientos aún más sangrientos que los previos? Quizás sí, y fue por eso que su séquito fue voluntariamente con los pehuenches $\mathrm{y}$, años luego, Calbullan retornó con los pehuenches.

En cuanto al último interrogante, consideramos que adquirir la amistad de Calbullan fue una decisión estratégica de Amigorena, porque aquel había vivido veinte años con los huilliches, por lo que podía brindar información sobre sus particularidades de lucha, estrategias, movimientos, costumbres y otros elementos que podían permitirle a los hispano-criollos y pehuenches conocer aun más a su enemigo.

Por otra parte, en la copia del oficio del 16 de febrero de 1792 y en el oficio del 18 de febrero de ese mismo año, Amigorena menciona que el comandante interino del fuerte de San Carlos (Juan Morel), le envió un oficio fechado el 14 de febrero de 1792, ${ }^{23}$ mediante el cual le informó que llegaron a ese fuerte dos indios del cacique pehuenche Roco avisando que los caciques huilliches Buenhumilla ${ }^{24} \mathrm{y}$ Querahueque atacaron las tolderías de Currilipi (o Currilepi, cacique principal de los pehuenches de Balbarco) asentadas en la laguna "...Renilebue..." ${ }^{25}$ dándole muerte a él y a varios de sus indios. La noticia del ataque se difundió desde la mismísima toldería ya que un capitanejo logró huir y le informó del hecho a Pichintur. Este mandó aviso al cacique Roco, quien para la época se encontraba viviendo a orillas del Diamante. A continuación, Roco despachó dos correos al fuerte de San Carlos y junto a Pichintur decidieron salir al alcance de los atacantes huilliches. ${ }^{26}$

En primer término, cabe comentar que no es sorprendente que la información de los movimientos enemigos y del ataque haya llegado al fuerte de San Carlos por vía de indios de Roco, siendo este accionar correspondiente a sus funciones como "indio amigo". ¿Pero cómo llegó ese cacique pehuenche de Malargüe a serlo? Como explicamos con anterioridad, durante la campaña de Amigorena al cerro Campanario varios caciques fueron asesinados, entre ellos, el pehuenche Guentenao (Amigorena, 1969 [1780]). Tras ello, Roco - quien estaba casado con su hija, Ignacia Guentenao(Hux, 1993) lo sucedió como líder indiscutido. La mayoría de los capturados por el comandante en esa expedición eran de la parcialidad de Guentenao y Roco por lo que este fue uno de los primeros en dirigirse a Mendoza para negociar, siendo seguido por otros caciques pehuenches. Todos ellos se comprometieron a ser "indios amigos" de los españoles de Mendoza, lo que implicó unírseles para arrojarse contra los indígenas infieles (para la época, los pampas y huilliches y ranqueles) y avisarles sobre los planes o movimientos de los enemigos de tierra adentro (Roulet, 1999-2001). Por parte de los 
mendocinos, no atacar las tolderías de los "indios amigos" y auxiliarlos con armas y hombres en su accionar contra los enemigos (Roulet, 1999-2001). ${ }^{27}$

Asimismo, un pequeño número del total de los pehuenches de Malargüe -entre ellos el cacique Roco y los suyos- debió aceptar la condición de asentar sus tolderías “...más de 200 kilómetros al norte, en las inmediaciones del fuerte de San Carlos" (Roulet, 1999-2001, p. 207) conformando así un enclave con funciones militares, logísticas, diplomáticas y económicas, sirviendo como antemural para frenar invasiones enemigas (Roulet, 1999-2001) y pasando a ser denominados pehuenches fronterizos. ${ }^{28}$

Volviendo a la fuente y focalizándonos en Pichintur y Currilipi, el primero de ellos era hermano del cacique pehuenche de Malargüe, Ancanamun. En 1785, junto a él y otros hermanos, y en su condición de "indios amigos", desarrollaron la matanza de Creyo (yerno del jefe ranquel Paillatur) y su familia (Roulet, 2016). Esta matanza renovó el odio ranquel para con la parcialidad liderada por Ancanamun. Así Llanquetur lideró a 2.000 ranquelches los cuales “...arrasaron las tolderías pehuenches desde el sur del Neuquén hasta llegar a los toldos de Ancán” (Roulet, 2016, p. 97). En dicho accionar afectaron las tolderías de los pehuenches de Malargüe y las de Balbarco. Entonces, los pehuenches de Balbarco estaban siendo asediados por los huilliches ${ }^{29} \mathrm{y}$ corrían riesgo de ser exterminados o absorbidos por los huilliches dado que los de Balbarco vivían "... en distancia de estos [los huilliches] como dos días de camino en sus inmediaciones del otro lado del caudaloso río Neuquén donde los demás pehuenches de este lado no los pueden favorecer casi, por las crecientes considerables del río..." (León Solís, 2001, p. 184). ${ }^{30}$ Entonces, su supervivencia dependía del apoyo que recibieran de sus parientes de Malargüe o de las comunidades asentadas en el río Laja y el Biobio (León Solis, 2001). Por su parte, a los pehuenches de Malargüe les era imposible seguir defendiendo sus tolderías y la frontera si no lograban aunar sus fuerzas con las de sus parientes los lonkos de Balbarco, Lolco, Villucura y Antuco, con quienes desde comienzos del siglo habían experimentado disputas y segmentarismo.

Tras la muerte de Ancanamun, Pichintur lo sucedió en el cacicazgo entre 1787 y 1796 (Villar y Jiménez, 2003). En octubre de 1787 participó del Parlamento del Salado con varios funcionarios mendocinos y los pehuenches de Balbarco, representados por su cacique Currilipi. En esa ocasión:

Pichintur en representación de los demás caciques declaró su amistad, subordinación y fidelidad siendo legítimos vasallos del soberano y amigos del gobierno, prometiendo lealtad y obediencia a la monarquía y que en lo sucesivo guardarían rendida obediencia y subordinación en cuantas órdenes se les impartiesen. Además prestaban toda su cooperación en la lucha contra los huiliches y ranquilches, avisando de cualquier actividad que desplegasen los enemigos que subsisten en el paraje nombrado 'Mamuel Mapú'... (Comando General del Ejército, 1973, p. 61).

Con ese Parlamento se forjó el nuevo eje Mendoza, pehuenches de Malargüe y pehuenches de Balbarco, que significó la mejor defensa y ofensa contra los huilliches. ${ }^{31}$ La alianza se materializó con toda su fuerza en 1788, cuando se emprendieron múltiples campañas contra las fuerzas de Llanquetur y sus aliados que fueron rápidamente contestadas. En diciembre, una nueva expedición conformada por pehuenches (entre ellos, Currilipi y Pichintur) e hispano-criollos de ambos lados de la cordillera salieron en búsqueda de los huilliches asentados en Neuquén y lograron poner fin a la vida de Llanquetur. No obstante, como era de esperarse, las hostilidades entre ambos bandos no cesaron, y esto lo confirma el contenido narrado en nuestro documento. 
Entonces, dando cumplimiento a lo pactado en el Parlamento del Salado, Pichintur ordenó a uno de su parcialidad comunicar la noticia del asesinato de Currilipi a Roco, para que éste lo hiciera llegar a los hispano-criollos. Pero también actuando acorde a lo pactado, salió con Roco (y otros caciques) a perseguir a los agresores y en auxilio de los sobrevivientes del ataque. Por otra parte, no hay que perder de vista que Pichintur y Roco eran pehuenches de Malargüe, quienes estaban conectados con los de Balbarco por múltiples lazos de parentesco. Sin ir más lejos, Pichintur era primo de Currilipi (Roulet, 2016), entonces, estas ansias de salir en búsqueda de los huilliches-ranqueles pudo darse con el fin de perpetrar lo que Boccara (1998, citado en Villar y Jiménez, 2003) denomina tautulun: vengar la muerte ocasionada a una persona emparentada. Volviendo a la fuente, ante la noticia del ataque huilliche y consecuente asesinato de Currilipi, Amigorena se ve sensibilizado y preocupado:

...por la utilidad que resultara a nuestras fronteras de la situación en que se hallava este Cacique, que era un Parage en donde precisamente cortava la internación a los Huilliches, hostilizándolos manteniéndole una Viva Guerra, sin havernos cauzado él, ni su Yndiada jamás un medio $\mathrm{rr}^{\mathrm{S}}$. de gasto... ${ }^{32}$

Al igual que para el caso de la frontera de Arauco que analiza Ruiz Esquide Figueroa (1993), la ayuda militar brindada por los "indios amigos" a las autoridades mendocinas fue esencial para la estabilización de esa frontera y el ahorro de fondos. En Mendoza no había disponible una gran cantidad de armamento (ni en buenas condiciones) ${ }^{33} \mathrm{ni}$ tampoco recursos humanos. Además, entre 1769 y 1778, a causa de malones, la guarnición del fuerte de San Carlos quedó diezmada en varias oportunidades y tuvo que ser repuesta, pero logrando tan solo llegar a un total de 25 milicianos de manera constante, que poco podían hacer frente al continuo avance indígena (Comando General del Ejército, 1973, p. 18). Entonces, se puede advertir que la alianza pehuenche le evitó a la administración colonial caer en gastos mayores y regulares como sería, por ejemplo, que los pocos milicianos presentes en el fuerte de San Carlos debieran hacer recorridas del territorio.

Por otra parte, en el mismo oficio Amigorena manifestó que posiblemente: “...estos Pehuenches han de pedir incesantemente auxilio de Milicianos para Destacamentos, y salidas contra sus Enemigos, porque es presumible que [...] quieran venir contra estos otros, y serán inexcusables los gastos que se cauzarán en el año de $92, \ldots . . .{ }^{34}$ Este pedido pehuenche de auxilio militar era algo recurrente dentro de la lógica de reciprocidad entre hispano-criollos e "indios amigos".

En la fuente también se advierte que el comandante quedó sorprendido por la muerte del cacique Currilipi, pero el conflicto interétnico es detallado en el escrito persiguiendo una intencionalidad particular: poner sobre el tapete cómo aumentarían los gastos de su administración. En palabras de Amigorena:

...no deja de serme bastante sencible esta noticia por la utilidad que resultara a nuestras fronteras de la situación en que se hallava este Cacique, que era un Parage en donde precisamente cortava la internación a los Huilliches, hostilizándolos manteniéndole una Viva Guerra, sin havernos cauzado él, ni su Yndiada jamás un medio $\mathrm{rr}^{\mathrm{s}}$. de gasto: Con este motibo, ya veo que estos Pehuenches han de pedir incesantemente auxilio de Milicianos para Destacamentos, y salidas contra sus Enemigos, porque es presumible que haviendo estos salido bien en el debate, quieran venir contra estos otros, y serán inexcusables los gastos que se cauzarán en el año de 92, los que se ahorraban en gran parte con la defensas que hazía Currulipi conteniendo en sus terrenos a el enemigo... ${ }^{35}$

Queda clara entonces la preocupación de Amigorena por las consecuencias que este suceso podía traer en su frontera, en términos de desprotección y gastos indeseados. 
Entonces, para evitar la llegada a la ciudad de Mendoza de los caciques con el pedido de una intervención hispano-criolla más numerosa y onerosa, Amigorena decidió mandar a los toldos de Pichintur al Capitán de Amigos ${ }^{36}$ Carlos Bosa (o Boza), junto a dos veteranos, un miliciano y dos indios ladinos lenguaraces, para investigar la veracidad de la noticia de la derrota y muerte de Currilipi y tratar con los caciques de los "indios amigos". ${ }^{37}$

La inquietud del comandante no resulta infundada y era compartida por varios de los sujetos que figuran en estos documentos. Los ministros de Real Hacienda expresaron también su preocupación, porque acordar amistad con Calbullan implicaba entregarle regalos y ponerse en gastos. ${ }^{38} \mathrm{En}$ un oficio del día siguiente -para respaldar aún más su postura- comentan que de acuerdo a las cuentas del fuerte de San Carlos, los fondos recibidos ese año solo alcanzaban para mantener durante los primeros cuatro meses a la guarnición en virtud de los cuantiosos gastos generados por los "indios amigos". ${ }^{39}$ Sobre este mismo punto se expidió el gobernador intendente Sobremonte en oficio del 15 de marzo de 1792, indicando que los gastos destinados a los "indios amigos" no pueden eliminarse dado que son: “...siempre inferiores a los que ocasionaría la manutención de la Guerra con aquellos no fieles y con estos que dejarían de serlo si les faltase...". ${ }^{40}$ Asimismo, debía atenderse al pago de haberes - sin retardo- para la guarnición de San Carlos, para así evitar que los sujetos abandonaran sus plazas ${ }^{41}$ De todo ello se desprende que los gastos en agasajos y mantenimiento de indígenas, cuando bajaban a la ciudad, fueron indispensables para mantener a los "indios amigos" como tales. Además, su colaboración fue vital para el mantenimiento de la estabilidad fronteriza.

Aunque la fuente que traemos en esta ocasión por sí misma no nos permite conocer el impacto que el ataque a Currilipi generó en los pehuenches, sabemos que “...la toldería de Barbarco había sido virtualmente destruida" (León Solís, 2001, p. 213) teniendo en cuenta la cantidad de muertos, cautivos y animales tomados. Por ello, desde el mismo momento del ataque, Pichintur propuso realizar una operación combinada de guerreros y cuerpos militares hispano-criollos de ambas vertientes de los Andes. Ese plan se concretó entre el 15 de mayo y el 18 de julio de 1792. Desde Mendoza partió un contingente de 40 hombres al mando del capitán Esquivel Aldao, junto a varios caciques y sus guerreros. Entre los vinculados con nuestras fuentes, identificamos a Pichintur, Roco y Calbullan. Este frente se unió a las fuerzas de Penco lideradas por Lorenzo Obando y formadas por 35 hombres armados de fusiles y lanzas y los caciques Linganualu, Coleguinca y Carilon junto a su indiada, en auxilio de los indios amigos pehuenches y contra los huilliches-ranqueles, llegando a un total de 350 hombres armados (León Solís, 2001, p. 232). Este suceso es importante para nuestro estudio porque nos cuenta la reacción que los aliados pehuenches-hispano-criollos desempeñaron luego del ataque a las tolderías de Balbarco, además de que da cuenta del acuerdo y acción conjunta entre las autoridades de Concepción y Mendoza, así como del afianzamiento de la alianza hispano-criollos y pehuenches (León Solís, 1982).

\section{Consideraciones finales}

A modo de cierre, podemos observar que la presente documentación resulta de gran interés debido a que brinda información sobre el desempeño de la alianza pehuencheshispano-criollos de Mendoza en la lucha contra un enemigo común: los huillichesranqueles. Asimismo, nos permitió reparar en la actuación que los "indios amigos" 
asumieron en cumplimiento con lo pactado con las autoridades coloniales en el marco de un conflicto que los implicó doblemente: como aliados de los blancos y enemigos de los huilliches-ranqueles y como pehuenches parientes y aliados de los agredidos. En tercer término, nos permitió concluir que el ataque a las tolderías de Currilipi fue de gran envergadura, aunque esperable, ya que este cacique había sido un activo partícipe en las campañas coordinadas contra los huilliches-ranqueles; formó parte de la expedición que ajustició a Llanquetur; entregó la cabeza del vencido al comandante de la Plaza de los Ángeles (León Solís, 2001) y cautivó gran cantidad de personas albergándolas en sus tolderías. Por ello, Currilipi y los suyos fueron incesantemente amenazados (y también agredidos) por los huilliches-ranqueles en sus intentos de vengar a sus caídos y rescatar cautivos, por lo que el ataque era inminente. Sumado a ello, como explica León Solís (2001), la toldería de Balbarco estaba localizada en la periferia de la "pehuenchada" por lo que era un objetivo militar fácil para los agresores asentados cerca, pero difícil para los otros pehuenches para auxiliarlos, sobre todo porque no podían aumentar sus fuerzas rápidamente - a diferencia de sus enemigos ${ }^{42}$ ya que el reclutamiento se basaba en los lazos de parentesco, y en el contexto de las relaciones fronterizas, esos estaban deteriorados.

A su vez, pudimos identificar el auxilio hispano-criollo brindado tras ese ataque y reparar en la carencia de armamento en buen estado y de hombres para la defensa de la frontera de Mendoza. Sumado a ello, la insuficiente disponibilidad de recursos financieros para hacer frente a los gastos que implicaba cumplir con las obligaciones para con los "indios amigos" y además mantener a la guarnición del fuerte de San Carlos. Si bien en este escrito no nos hemos planteado analizar este tema, el mismo pasará a formar parte de nuestra agenda de trabajo futura dado que es un elemento recurrente en la documentación y que nos invita a problematizar y reflexionar sobre el margen de negociación que tuvieron las autoridades hispano-criollas con las parcialidades indígenas en dicho contexto.

Por último, el caso del cacique Calbullan que abandonó su parcialidad pehuenche para internarse con los huilliches, con quienes tejió lazos comunales y de parentesco, nos permitió corroborar que las identidades étnicas de las agrupaciones nativas de la época bajo análisis eran permeables y cambiantes y que se veían expuestas a complejos procesos de mestizajes y aculturaciones. Por otra parte, también nos permitiría confirmar que, como indica Roulet (2011), la adopción de una nueva identidad no borraba la anterior sino que esta permanecía latente hasta que alguna situación particular, o riesgosa, la reactivara y generara: “...la nostalgia del emigrante y el deseo de volver a la tierra donde reposaban los restos de sus antepasados" (Roulet 2011, p. 242). Para el caso de Calbullan, quizás el haber vivido el enfrentamiento entre huilliches-ranqueles e hispano-criollos y pehuenches en las propias tierras que lo acogieron como emigrado y advertir que no sería un ciclo que se cerraría de forma ventajosa para los huilliches-ranqueles, hicieron que optara por decidir volver a sus tierras ancestrales y a su Nación pehuenche, pactar con los hispano-criollos de Mendoza y luego participar de la expedición combinada de 1792.

\section{Fuentes}

2 Archivo General de la Nación (AGN), sala IX, División Colonia, Sección Gobierno. Legajo 24.2.2, Guerra y Marina (1792), Expediente $\mathrm{N}^{\circ} 19$. 


\section{Transcripción del documento} veinte años a esta parte; $y$ de las ventajas $q^{e}$. ofrece la amistad del referido $y$ haver concedido a todos $\mathrm{q}^{\mathrm{e}}$. el soldado Carlos Boza sirva de Capit ${ }^{n}$. de Amigos, añadiendo VS. haverse detenido en aprobarlo $p{ }^{r}$. la fundada duda de $q$ e. no le haya movido otro interés a dho Calbullan, $\mathrm{q}^{\mathrm{e}}$. el de estar unido al Partido más pujante, y no el de seguir la inclinac ${ }^{\mathrm{n}}$., que nos tenga, ni a los de su Nación, como también, $\mathrm{p}^{\mathrm{r}}$. el aumento de gastos de regalos $\mathrm{q}^{\mathrm{e}}$. ocasionará este nuebo Amigo, y la escasez de los ramos $\mathrm{q}^{\mathrm{e}}$. los Fr fren [?] Enterado de todo prevengo á Vs. $\mathrm{q}^{\mathrm{e}}$. como el acierto de la resoluc ${ }^{\mathrm{n}}$ de aquel Comandante de Front ${ }^{a}$ deve principalm ${ }^{\text {te }}$, discernirse $\mathrm{p}^{\mathrm{r}}$. el conocim ${ }^{\text {to }}$. del carácter de aq llos.Yndios y de las demás circunstanc [ias] ${ }^{73}, \mathrm{q}^{\mathrm{e}}$. influyan en la sincerid ${ }^{\mathrm{d}}$. $\mathrm{y}$ En oficio de 19, del corr te. me comunica VS el aviso $q^{e}$. le dio el Comand ${ }^{\text {te }}$. de Front a. de Mendoza de haver concedido la Paz q e. llegó a pedirle el Cacique Calbullan, en Comp permanencia de la amistad solicitada $\mathrm{p}^{\mathrm{r}}$. Calbullan, y en el efecto de su promesa de engrosar el partido de los Pehuenches, y devilitar el de los Huilliches, en lo q ${ }^{\text {e. }}$. devemos suponer con mas intelig a, al mismo Comand ${ }^{\text {te }} \cdot \mathrm{p}^{\mathrm{r}}$. su larga experiencia de ellos $\mathrm{y}$ trato con los primeros de estos, es necesario q.e mientras las ocurrencias no persuadiesen lo contrario, continúe cultivándose la amistad $\mathrm{q}^{\mathrm{e}}$. ofreció a dho Cacique aunque con la precauc $^{n}$. $q^{e}$. exige su anterior conducta; y suplementos necesarios $p^{a}$. el aumento de los gastos $\mathrm{q}^{\mathrm{e}}$. VS. reconoce indispensables $\mathrm{p}^{\mathrm{a}}$. la quietud de las Fronteras, la $\mathrm{q}$ e. ciertamente excusa otros de mayor considerac ${ }^{\mathrm{n}}$. = Dios Guíe á Vs. mu. ${ }^{\mathrm{s}}$ a ${ }^{\mathrm{s}}$. Buenos Ayres 24 de Diciembre de 1791; = Nicolás de Arredondo $=\mathrm{S}^{\mathrm{r}}$. Gov. ${ }^{\text {or }}$. Ytend te. de Cordova.

\section{Es Copia}

19 Josef de la Barreda [firmado]

20 
Carlos $\mathrm{D}^{\mathrm{n}}$. Juan Morel, impondrá a VS del abanze que dieron los Huilliches, al Cacique Pehuenche Currilipi, y cómo lo han muerto a él, y a muchos de sus Yndios, y de la resolución tomada por Pichintur de seguir a los Enemigos: no deja de serme bastante sencible esta noticia por la utilidad que resultava a nuestras fronteras de la situación en que se hallava este Cacique, que era un Parage en donde precisamente cortava la internación a los Huilliches, hostilizándolos y manteniéndole una Viva Guerra, sin havernos cauzado él, ni su Yndiada jamás un medio rrl. de gasto: Con este motibo, ya veo que estos Pehuenches han de pedir incesantemente auxilio de Milicianos para Destacamentos, y salidas contra sus Enemigos, porque es presumible que haviendo estos salido bien en el debate, quieran venir contra estos otros, y serán inexcusables los gastos que se cauzarán en el año de 92, los que se ahorraban en gran parte con la defensas que hazia Currulipi conteniendo en sus terrenos a el enemigo: Yo para atajar los gastos que se ocasionarían si viniesen los Caciques trayendo esta noticia como es regular, he dispuesto mandar a los Toldos de Pichintur, al Cap ${ }^{n}$ de Amigos Carlos Bosa con dos Beteranos, un Miliciano, y dos Yndios ladinos Lenguaraces de esta frontera, con una Ynstrucción que le he dado para que con arreglo a ella trate con los Caciques quanto le prevengo; Para Socorrer esta Partida he passado el correspondiente oficio a estos Ministros de R ${ }^{1}$. Hazienda, de que incluyo a Vs. copia, e igualmente la de su Contextación, como assí mismo otra del oficio que me pasaron sobre si debería preferir el pago de la Guarnición, o el de los Gastos de los Yndios amigos, a que se sigue copia de mi contextación para la inteligencia de VS, pues hasta ahora no se ha verificado pago alguno por la escazes de los Ramos y por que alegan los Ministros que las orns Superiores no declaran señaladamente de que Caudales se haya de echar mano en un caso de necesidad, que no faltaran varios de esta naturaleza de aquí a delante, según me persuado, sobre cuyo punto tomará VS. la resolución que fuera de su Superior arbitrio.

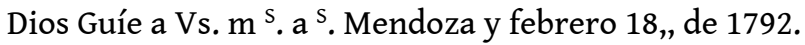

Jossef Fran co de Amigorena [firmado]

Sor Marques de Sobremonte

[al margen]

354.

Oficio Hallándose esta Contaduría ajustando la Guarnición del Fuerte de San Carlos por el haver de todo el año próximo passado de mil setecientos noventa y uno, y reconocido que los fondos de los Ramos con inclusión de los Suplementos con que se le ayudan, no alcanzan más que a satisfacer a dha Guarnición que en los primeros quatro meses del citado año, se ha visto senciblemente que la cauza de esta debilidad la producen los demasiados Gastos con que se socorren a los Yndios amigos que vienen a esta Ciudad; pues que en el citado año por las cuentas q.e Vm tiene remitidas, y ya están pagadas ascienden a la cantidad de 1453 p 3/4 $\mathrm{rr}^{\mathrm{s}}$. . En cuya virtud se há acordado para en adelante que ese, o se ha de atender solo a la Guarnición, o a los Yndios amigos, que Vm vea, y premedite qual de estos dos servicios es mas importante y que por tal se Satisfaga con mayor prontitud; pues hallándonos como hasta aquí comprometidos a uno, y otro objeto, nada otra cosa se alcanza que repetir las confusiones, y quexas que promueben 
las necesidades de los Ynteresados. Vm explique claramente lo que combenga mas al Servicio del Rey y de la Patria para según su declaración proceder en los términos indicados = Dios Guíe a Vm. $\mathrm{m}^{\mathrm{s}}$. a ${ }^{\mathrm{s}}$. Mendoza y febrero 11 de $1792=$ José Ant ${ }^{\circ}$.Palacio =Señor Comandante de Armas $\mathrm{D}^{\mathrm{n}}$ José Fran $^{\mathrm{co}}$. de Amigorena=

Contextaz on En Oficio de este día, me dizen Vms q ${ }^{\text {e }}$. hallándose ajustando las Cuentas de la Guarnición de $\mathrm{S}^{\mathrm{n}}$ Carlos, $\mathrm{p}^{\mathrm{r}}$. el haver de todo el año próximo pasado de 1791, han reconocido, que los fondos de los Ramos con inclusión de los Suplementos con q ${ }^{\mathrm{e}}$. se le ayudan, no alcanzan a mas de $\mathrm{q}^{\mathrm{e}}$. a Satisfacer a dha Guarnición los primeros quatro meses del citado año; Cuya cauza procede de los Gastos $\mathrm{q}^{\mathrm{e}}$. cauzan los Yndios amigos q e. vienen a esta ciudad. En cuya virtud, y en la de decirme [les explique claram[ente] $\left.{ }^{44}\right]^{45}$ Vm qual de los dos advitrios [sic: arbitrios] sea mas combeniente al servicio del Rey, y de la Patria, esto es, si se ha de atender primero a la Guarnicion, o a los Gastos de los Yndios amigos; devo responderles que a la Guarnición se le contribuye con la carne, tabaco, demás menesteres, y q ${ }^{\mathrm{e}}$ aun se les abona por el Habilitado el Bestuario en donde quieran tomarlo, $\mathrm{q}^{\mathrm{e}}$ en estos términos deve ser preferible el mantenimiento de la carne subministrada a la Guarnicion por $\mathrm{D}^{\mathrm{n}}$. Fran ${ }^{\mathrm{co}}$. Xavier de Rozas, y $\mathrm{p}^{\mathrm{r}}$. otros Ynteresados $\mathrm{q}^{\mathrm{e}}$ han hecho estos Suplementos, $\mathrm{q}^{\mathrm{e}}$ en Segundo lugar deven abonarse los indispensables Gastos q ${ }^{\mathrm{e}}$. Cauzan los Yndios amigos, que vajan a esta Ciudad a sus comercios, y lo que es mas a participar las noticias de los mobimientos de las Naciones enemigas, en $\mathrm{q}^{\mathrm{e}}$. se interesan las Fronteras del Virreynato; las $\mathrm{q}^{\mathrm{e}}$. haviendo yo comunicado al Superior Govierno conforme las iban trayendo los Yndios amigos, con Ynforme al mismo tiempo de los Gastos $\mathrm{q}^{\mathrm{e}}$. con este motibo ocasionan, resulta de ellas la aprobación de estos por la misma Superioridad, según las varias orns $\mathrm{q}^{\mathrm{e}}$ tiene esta Comandancia, y les consta a Vms. Y por las Ultimas $\mathrm{q}^{\mathrm{e}}$ acabo de recevir [sic: recibir] su fha 15, de próximo mes pasado, de $\mathrm{q}^{\mathrm{e}}$ están Vms entendidos Hechos estos abonos, se tendrán presentes las prevenciones del Superior Govierno, para hazer los Pagos a la Guarnición con arreglo a los Caudales de los Ramos destinados a la frontera, y orns $\mathrm{q}^{\mathrm{e}}$ deven regir en tal caso = Dios Guíe á Vms $\mathrm{m}^{\mathrm{S}}$. a ${ }^{\mathrm{S}}$. Mendoza 15 de febrero de $1792=$ José Fran ${ }^{\text {co }}$ de Amigorena $=$ Señores Ministros de $\mathrm{R}^{1}$. Hazienda de esta ciudad $=$

Oficio A las 6. horas del día de esta madrugada, he recivido Oficio del Comand ${ }^{\text {te }}$. Ynterino del Fuerte de $\mathrm{S}^{\mathrm{n}}$. Carlos por el $\mathrm{q}^{\mathrm{e}}$. me comunica haver llegado dos Yndios correos del Cacique Pehuenche Roco, avisándome q ${ }^{\mathrm{e}}$ el Cacique Gov or Pichintur le avisava, q haviendo escapado el Capitanejo de tal de los de la Toldería del Cacique nro amigo Currulipi, $\mathrm{q}^{\mathrm{e}}$ haviendo sido imbadido ahora ocho días por los Caciques Huilliches Buen_humilla, y Querahueque, fue muerto dho Curulipi, y muchos de una, y otra parte, y q ${ }^{\mathrm{e}}$. en substancia salió dho Pichintur con su Yndiada y algunos más de los de Roco en seguimiento, y alcanze de los expresados Huilliches. En esta inteligencia, y arreglado a las orns Superiores con $\mathrm{q}^{\mathrm{e}}$ me hallo para en tales casos, he dispuesto por ahora el $\mathrm{q}^{\mathrm{e}}$. se ponga en marcha, $\mathrm{p}^{\mathrm{a}}$. las Tolderías del expresado Caciq ${ }^{e}$ Pichintur, el Capitán de amigos $\mathrm{D}^{\mathrm{n}}$. Carlos Bosa acompañados de dos Beteranos, un Miliciano, y dos Yndios amigos Lenguaraces de esta frontera $\mathrm{p}^{\text {a. }}$ esclarecer, $\mathrm{y}$ tratar con los Caciques amigos, $\mathrm{q}^{\mathrm{e}}$ certidumbre tenga esta noticia, y demás providencias $q^{\mathrm{e}}$ sobre el particular hayan tomado a fin de premeditar las $\mathrm{q}^{\mathrm{e}}$ por mi particular devere tomar en caso necesario; $\mathrm{p}^{\mathrm{a}}$ cuyo fin se haze indispensable socorrerles prontamente por el tiempo $\mathrm{q}^{\mathrm{e}}$ se mantengan en dhas Tolderías con la carne, tabaco, Papel [?] ${ }^{46}$, en esta Virtud, y a fin de $\mathrm{q}^{\mathrm{e}}$ no se demoren, mando con esta fha al expresado Comand ${ }^{\text {te }}$ Ynterino les auxilie con Caballos, $\mathrm{y}$ demás raciones de lo $\mathrm{q}$ tubiese de su gasto: previniéndole $\mathrm{q}^{\mathrm{e}}$ remita a su regreso la Cuenta de estos Suplementos, lo $\mathrm{q}^{\mathrm{e}}$ aviso a Vms $\mathrm{p}^{\mathrm{a}}$. su govierno, e inteligencia; de cuya 
noticia doy parte $a \mathrm{~S}{ }^{\text {or }}$. Gov ${ }^{\text {or }}$. Yntendente de la Prov ${ }^{\mathrm{a}}$. $\mathrm{p}^{\mathrm{r}}$. el próximo Correo. = Dios Guíe á Vms $\mathrm{m}^{\mathrm{s}}$. a ${ }^{\mathrm{s}}$. Mendoza 16 de febrero de $1792=$ José Fran ${ }^{\mathrm{co}}$. de Amigorena = Ss res. Ministros de $\mathrm{R}^{1}$. Haz ${ }^{\text {da }}$. de Mendoza =

Contextaz ${ }^{\text {on }}$. Esta bien que Vm aya dispuesto auxiliar a Carlos Bosa, dos Beteranos, y dos Yndios amigos Lenguaraces para los fines $\mathrm{q}^{\mathrm{e}}$. expresa el oficio de Vm de la fha de esta, Siempre que remita Vm una razón instruida del tiempo y raciones con que deva auxiliárseles, y las declare por diligencias precisas al $\mathrm{R}^{\mathrm{l}}$. Servicio = Dios Guíe a Vm m ${ }^{\mathrm{s}}$. a s. Mendoza y febrero 16 de $1792=$ José Ant $^{\circ}$. Palacio $=\mathrm{S}{ }^{\text {or }}$. Comand ${ }^{\text {te }}$. de Armas de Mendoza $\mathrm{D}^{\mathrm{n}}$ José Fran ${ }^{\mathrm{c}}$. de Amigorena = sobre renglones $=$ les explique claramente $=\mathrm{V}$ es.

\section{Son Copias}

Jossef Fran co de Amigorena [firmado]

El Comandante Ynterino de la Frontera de S ${ }^{\mathrm{n}}$ Carlos D ${ }^{\mathrm{n}}$ Juan Morel con fha de 14 del corr ${ }^{\text {te }}$. me dize lo sig te.

Aqui llegaron dos Mosos de los de Roco, diciendo de que Pichintur le ha mandado dezir, de que haviéndose escapado el Capitanejo de tal de los de la Toldería de Curulipi; dice que haviendo sido imbocado (digo) imbadido ahora ocho días por los Caciques Huilliches Buenhumilla, y Querahueque, fue muerto dho Curilipi, y muchos de una y otra parte, y que la Batalla se les dio en la Laguna Renilebue en donde estaban apostados Currilipi con los Suyos, y que Pichintur salió ahora quatro días con los suyos, y algunos de los de Roco a darles alcanze = Esta es la Relación que me han hecho estos dos Mosos, cuya noticia aviso a Vm. por ahora, que si ocurre otra noticia de otra atención la participaré a Vm inmediatamente = Carilef, y Cumiñan Solicitan bajar a esa Ciudad, y piden Lizencia para ello, lo que aguardan de $\mathrm{Vm}=$ Dios Guíe á Vm $\mathrm{m}{ }^{\mathrm{s}}$. a $\mathrm{s}$. Villa de $\mathrm{S}^{\mathrm{n}}$. Carlos 14 de febrero de 1792= Juan Morel $=\mathrm{S}^{\text {or }}$. Comandante de Armas $\mathrm{D}^{\mathrm{n}}$ José Fran ${ }^{\text {co }}$. de Amigorena=

Cuya copia traslado a Vm para su inteligencia a efecto $\mathrm{q}^{\mathrm{e}}$ si $\mathrm{Vs}$ lo tiene por combeniente, se le comunique al Exmo $\mathrm{S}^{\text {or }}$. Virrey, por obmitirlo hazer en derechura por mi particular.

\section{Es Copia.}

\section{Amigorena [firmado]}

Enterado de la dispocisión del Exmo Señor Virrey que Vm nos comunica en su orden de quince del corriente, para que se continúen los gastos de agasajos con el Cacique Calbullan, como se executa con los demás amigos de la Nación Peguenche, solo se nos ofrece reparar lo mucho que recresen los gastos estas frequentes alianzas, y consiguientes visitas que sobre ellas recaen, y lo que debilitan el fondo de los Ramos para conserbar la guarnición que defiende la Frontera, de modo que, o se ha de suspender uno, u otro objeto, o la Real Hacienda ha de sufrirlo; en que haviendo hecho tantas representaciones, nos basta recordarlo á Vsia para que se sirva aplicar el más conveniente remedio $=$ Nuestro Señor Guíe a Vsia muchos años $=$ Mendoza y Febrero diez de mil setecientos noventa, y dos = José Antonio de Palacio = Señor Governador Yntendente Marques de Sobre Monte.

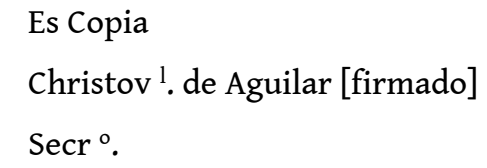




\section{Exmo. Señor}

Por la Copia numero $1^{\circ}$, se enterará VE del abanze que dieron los Yndios Huiliches al Cacique Peguenche Curulupi, y perjuicio que justamente teme el Comand ${ }^{\text {te }}$ de Mendoza por este suceso a Causa de que este Yndio amigo por sus fuerzas y situasión mas abanzada contenía mucho las irrupciones de aquellos contra los demás Peguenches sus aliados, y por consig te. las que podían dirijir á mas Front ${ }^{\mathrm{s}}$. haviendo tomado la providencia de hacer salir la pequeña Partida que refiere $\mathrm{p}^{\text {a }}$ tratar con los Caciques amigos lo que convenga según la instrucción que le ha dado al encargado de ella, y me avisa los oficios pasados con aquellos Ministros para la acostumbrada asistencia de esta Gente, y sobre quales gastos sean preferibles si los de la Guarnición del Fuerte de $\mathrm{S}^{\mathrm{n}}$. Carlos, o el que causan los Yndios amigos que bajan a aquella Ciudad sobre lo qual dhos Ministros me proponen duda en su oficio de 10 , del pasado del que es la Copia $n^{\circ} 2$.

Por lo que hace al primer punto les he aprobado la salida de dha Partida, y el oficio pasado para los gastos de su subsistencia con la adbertencia de que estando resuelto por Acuerdo dela Junta Superior de 16, de Julio de que spre que se hallen amenazadas estas Fronteras con justos recelos de ser imbadidas se hagan todos los necesarios para su defensa en qualesquiera Ramos en defecto de los de sisa[...] y Arbitrios destinados á ella, no tienen que dudar dhos Ministros porque esta dispocisión no se halla variada, antes fue expedida con conocimiento de las Salidas que varias vezes son indispensables, y refuerzos de la Front ${ }^{a}$ ocacionándolos la satisfasión del Prest que está asignado a las Milicias en tales casos en los que por la misma dispocisión pueden usar de los de la $\mathrm{R}$ ta. del Tabaco quando no alcanzen a los Suplem ${ }^{\text {tos }}$. los de $\mathrm{R}^{1}$. Hacienda como generalm te acontece por las dibersas atenciones que sobre si tienen, y que por lo que toca a quales deben preferirse si los de la Guarnición del Fuerte de $\mathrm{S}{ }^{\mathrm{n}}$ Carlos único de ella, o los de los agasajos de los Yndios que lo consultaría á VE como lo hago, pues demostrándose a lo que ascienden estos, y a que se aumentaran con la nueba alianza del cacique Calbullan (a que VE me ha mandado atender por su orn de 24 de Diziembre último) y lo mismo los de las salidas por dho suceso siempre inferiores a los que ocasionaría la manutención de la Guerra con aquellos no fieles y con estos que dejarían de serlo si les faltase, veo igualmente preciso que a dha Guarnición, que solo es de veinte y cinco hombres, se les satisfagan sus haveres sin retardo porque no tendrían de que subsistir, y seguram te dejarían sus Plazas si no se les pagase, para lo qual considero que es necesaria la misma graduasion de Suplementos de unos a otros Ramos en atención a que son indispensables aquellos que sobstienen dicha alianza con beneficio común de las Fronteras; y para afirmarme en este concepto, y no tener que trepidar en lo subsesibo [sic: sucesivo] para estas dispocisiones lo expongo a VE para que las suyas Superiores sirban de arreglo a las mías en semejantes casos.

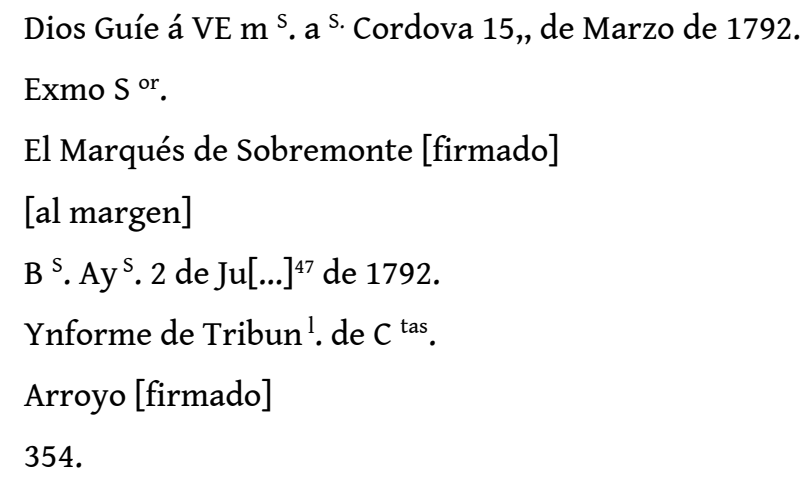




\section{BIBLIOGRAPHY}

Amigorena, J. 1969 [1780]. Diario de la expedición que de orden del Exmo. Señor virrey acabo de hacer contra los indios bárbaros peguenches. En P. de Angelis, Colección de obras y documentos relativos a la historia antigua y moderna de las Provincias del Río de la Plata, (tomo IV, pp. 203-220). Buenos Aires: Plus Ultra.

Comando General del Ejército (1973). Política seguida con el aborigen. Tomo II (1750-1819). Buenos Aires: Biblioteca del Oficial.

Durán, V. (1991-1992). Las poblaciones indígenas del sur mendocino durante los siglos XVI y XVII. Anales de arqueología y etnología, V(46-47), 9-40.

Durán, V. (1993-1994). La araucanización de las poblaciones indígenas del sur mendocino (siglos XVIII y XIX). Anales de arqueología y etnología, V. 48-99, 31-55.

Gascón, M. (2009). Recursos para la frontera Araucana: Santiago de Chile y Mendoza en el siglo XVII. TEFROS [online], VII (1-2), 1-17. Disponible en http://www.hum.unrc.edu.ar/ojs/index.php/ tefros/article/view/198

Gascón, M. (2011). Periferias imperiales y fronteras coloniales en Hispanoamérica. Buenos Aires: Editorial Dunken.

Hux, M. (1993). Caciques puelches pampas y serranos. Buenos Aires: Marymar.

León Solís, L. (1982). La Corona española y las guerras intestinas entre los indígenas de Araucanía, Patagonia y las Pampas, 1760-1806. Nueva Historia, Revista de Historia de Chile, II(5), 31-67.

León Solís, L. (2001). Los señores de las cordilleras y las pampas. Los pehuenches de Malalhue, 1770-1800. Mendoza: Universidad de Congreso/Municipalidad de Malargue.

Nacuzzi, L. (2002). Leyendo entre líneas: una eterna duda acerca de las certezas. En S. Visacovsky y S. Guber (Comps.), Historia y estilos de trabajo de campo en la Argentina, (pp. 229-262). Buenos Aires: Antropofagia.

Prieto, M. (1989). La frontera meridional mendocina durante los siglos XVI y XVII. Xama, 2, 117-131.

Roulet, F. (1999-2001). De cautivos a aliados: 'los indios fronterizos' de Mendoza (1780-1806). Xama, XII-XIV, 199-239.

Roulet, F. (2011). Identidades étnicas y territorios indígenas en la obra de don Luis de la Cruz: entre pehuenches, huilliches, llanistas, ranquelinos y pampas (1806). Revista Complutense de Historia de América, 37, 221-252.

Roulet, F. (2016). Huincas en tierra de indios: mediaciones e identidades en los relatos de viajeros tardocoloniales. Ciudad Autónoma de Buenos Aires: Eudeba.

Ruiz Esquide Figueroa, A. (1993). Los indios amigos en la frontera araucana. Santiago de Chile: DIBAM.

Tanodi, B. (2000). Documentos históricos. Normas de transcripción y publicación, Cuadernos de Historia, Serie Ec. y Soc., 3, 259-270.

Varela, G. y Manara, C. (2003). Desde la periferia a los centros de poder. Las relaciones interétnicas y sus articulaciones en las fronteras surandinas.1780-1880. En R. Mandrini y C. Paz (Eds.), La frontera hispano criolla del mundo indígena latinoamericano en los siglos XVIII y XIX, (pp. 
173-197). Tandil: IEHS, Universidad Nacional del Centro de la Provincia de Buenos Aires-CEHIR, Universidad Nacional del Comahue-Departamento de Humanidades, Universidad Nacional del Sur.

Villar, D. y Jiménez, J. (2003). La tempestad de la guerra: Conflictos indígenas y circuitos de intercambio. Elementos para una periodización (Araucanía y las Pampas, 1780-1840). En R.

Mandrini y C. Paz (Comps.), Las fronteras hispanocriollas del mundo indígena latinoamericano en los siglos XVIII y XIX, (pp. 123-196). Tandil: IEHS, Universidad Nacional del Centro de la Provincia de Buenos Aires-CEHIR, Universidad Nacional del Comahue-Departamento de Humanidades, Universidad Nacional del Sur.

\section{NOTES}

1. Esta investigación se realizó en el marco del PICT 2017-0662 denominado "Construcción de identidades, mestizajes culturales y estrategias políticas en las fronteras coloniales del sur de América", financiado por ANPCYT. Agradezco a los evaluadores externos por su lectura minuciosa y comentarios enriquecedores.

2. Aclaramos que es aproximado dado que los oficios y las contestaciones a los mismos están escritos de manera continuada, no están separados en diferentes hojas.

3. En esta oportunidad se ha hecho una selección de la documentación a transcribir y a analizar dentro de dicho expediente, dejando para posteriores trabajos un análisis profundo sobre la cuestión netamente económica y administrativa de la frontera mendocina. Así, se ha decidido excluir la documentación que se encuentra al final del Expediente y que se corresponde con el Tribunal de Cuentas, fechada mayoritariamente en 1796 y que detalla los gastos invertidos en la Partida que salió a los toldos del cacique pehuenche Pichintur, incluyendo las raciones recibidas y los haberes otorgados a algunos milicianos.

4. Las "gentes del pehuén" fueron grupos que vivieron a un lado y otro de la cordillera de los Andes, de acuerdo a las estaciones del año, y habitaban al sur del río Neuquén, en los boscosos valles de araucarias. Su territorio se extendía, a principios del siglo XVIII, hasta la región del Nahuel Huapi (Roulet, 2016). En el transcurso de ese siglo, en busca de tierras más propicias para el pastoreo y amparados por la pacificación de la frontera de la década de 1780, algunos grupos cruzaron el río Neuquén hacia el norte y se asentaron en la región de Malargüe (por ejemplo, el cacique Ancanamun) (Roulet, 2016). Estos pasaron a ser denominados pehuenches de Malargüe mientras que aquellos que permanecieron en el río Neuquén recibieron el de pehuenches de Balbarco (también pehuenches de los Piñones o pehuenches meridionales). Desde $1795 \mathrm{y}$ hasta 1798 los pehuenches de Malargüe y los de Balbarco estuvieron enemistados porque un cacique de Malargüe falleció durante una visita familiar en Balbarco y su muerte fue atribuida a una brujería (Roulet, 2016).

5. La "Gente del ranquel, o sea, de los carrizales o juncos" (Roulet, 2016, p. 77) habitó en Mamilmapu, región de la pampa central que tenía poca agua pero abundante vegetación y bosques de caldenes y arbustos espinosos que se extendía al este del Desaguadero, Salado o Chadileuvu y que era un terreno propicio para el buen engorde de ganado. Recibieron diferentes apelativos de acuerdo a quien los estuviera denominando; así fueron llamados huilliches ("gente del sur") orientales o de las pampas por parte de las autoridades chilenas, para distinguirlos de los huilliches que vivían al sur del rio Toltén, en la región de Valdivia. Por su parte, los pehuenches de Malargüe los denominaron huilliches y ranqueles. Si bien Mamilmapu no se encontraba al sur sino al este de su territorio, esta denominación puede estar indicando un origen meridional y cordillerano de los ranqueles (Roulet, 1999-2001). Esta pluralidad de 
denominaciones denota el complejo proceso de etnogénesis que los ranqueles vivenciaron (Roulet, 2016).

6. Para comprender dicha categoría, debemos remitirnos al Reino de Chile. Ruiz Esquide Figueroa (1993) realizó un exhaustivo estudio de los "indios amigos" en Chile y los define como aquellos que colaboraron con los hispano-criollos en el enfrentamiento contra los que se negaban a someterse (Ruiz Esquide Figueroa, 1993, p. 14). Aparte de la ayuda militar, debían servir de espías, de contención territorial del enemigo y debían llevar comunicaciones de un lugar al otro. Por ello, se les pagaba por sus acciones, recibían agasajos y regalos (Ruiz Esquide Figueroa, 1993).

7. Copia del oficio de Juan Morel a Amigorena. Villa de San Carlos, 14 de febrero de 1792. AGN, sala IX, División Colonia, Sección Gobierno. Legajo 24.2.2, Guerra y Marina (1792), Expediente $\mathrm{N}^{\circ} 19$.

8. Tal es el caso de palabras como 'Córdova', 'Yndios', 'Yntendente' que están presentes a lo largo de todo el escrito de la misma forma. Sin embargo, otras palabras tenían varias versiones ('Cazique', 'Casique', 'Lenguarases', 'Lenguarazes') por lo que decidimos unificar las formas y modificar las palabras del siguiente modo: 'Cacique' y 'Lenguaraces'.

9. Puelche se refiere a la "gente del este" de la cordillera, pequeñas bandas de cazadores nómades que poblaron desde tiempos prehispánicos los valles intercordilleranos, las lagunas de Guanacache y el río Diamante y las planicies que se extendían al este hacia el río Chadileuvu (Prieto, 1989). Fue un pueblo con presencia a ambos lados de los Andes y de los cuales se distinguieron diversos linajes: morcollames, oscollames, chiquillanes y goicos.

10. Durante el siglo XVIII los puelches recibieron el apelativo de pampas para diferenciarlos de las parcialidades cordilleranas denominadas pehuenches. Pero, además, al tener que internarse más tierra adentro buscando sal y ganado cimarrón, los hispano-criollos ampliaron el término pampa para pasar a denominar además a las parcialidades localizadas en las serranías de Ventania y Tandilia (Roulet, 2016).

11. Para más información sobre la situación de los puelches chiquillanes y hacia dónde se dirigieron tras el levantamiento, véase Roulet (1999-2001, 2016).

12. La enemistad entre estos y los pehuenches no se debía a un componente étnico (León Solís, 2001; Roulet, 2016) en virtud de que ambas sociedades vivenciaron procesos de mestizaje y mutua aculturación (León Solís, 2001). Por el contrario, comenzó con una venganza de sangre de la década de 1770 cuando - de acuerdo al relato de un cautivo escapado de las tolderías ranquelesel cacique Guelan (cacique principal de Mamilmapu) mató al padre de Ancanamun (pehuenche). Este conflicto finalizó en 1799, cuando el cacique Carripilun se apersonó en el fuerte de San Carlos para sellar las paces con los pehuenches comprometiéndose a ser amigos de los españoles y velar sobre los movimientos de los enemigos huilliches. Como demuestra Roulet (2016), este tratado: “...reflejaba una definitiva disociación entre los etnónimos ranquelche y huilliche, ahora percibidos como entidades distintas y enemistadas entre sí...” (p. 85). A partir de ese momento, los huilliches asentados en Neuquén quedaron política y militarmente aislados y debieron prescindir de sus previos aliados - los ranqueles- aunque mantuvieron vínculos comerciales con los habitantes de la Pampa y de Chile (Roulet, 2016).

13. Luego de la campaña militar lanzada desde todas las fronteras del Virreinato del Río de la Plata en este año, algunos huilliches se refugiaron en los bosques y lagos de la ladera oriental al sur del río Neuquén (Roulet, 1999-2001), por eso, generalmente se les suele adjudicar una ubicación al sur del territorio pehuenche “...en la Tierra de las Manzanas...” (Roulet, 2016, p. 98).

14. Ancanamun se encontraba liderando ataques en las fronteras de Buenos Aires (Amigorena, 1969 [1780]).

15. Sobre las negociaciones previas entre él y las autoridades de Chile, véase León Solís (2001) y Villar y Jiménez (2003).

16. Tras estas negociaciones, el apelativo huilliche fue usado para indicar una “...opción política contraria a la alianza con los españoles" (Roulet, 2016, p. 270). De modo que la pertenencia étnica 
pehuenche va a aludir a los indígenas aliados y amigos, mientras que la huilliche, referirá a los indígenas del sur de Neuquén y del Mamilmapu que eran enemigos y hostiles al dominio español. 17. También controlaban los campos de invernada ubicados al oriente de la cordillera entre los ríos Atuel y Barrancas, las aguadas y vados por donde pasaban las rutas maloqueras hacia las pampas o la costa atlántica desde Neuquén y Araucanía, y el intercambio con fuertes y diversos poblados (Varela y Manara, 2003; Durán, 1991-1992).

18. Copia del oficio de Arredondo a Sobremonte. Buenos Aires, 24 de diciembre de 1791. AGN, sala IX, División Colonia, Sección Gobierno. Legajo 24.2.2, Guerra y Marina (1792), Expediente $\mathrm{N}^{\circ} 19$.

19. Copia del oficio de Arredondo a Sobremonte. Buenos Aires, 24 de diciembre de 1791. AGN, sala IX, División Colonia, Sección Gobierno. Legajo 24.2.2, Guerra y Marina (1792), Expediente №19.

20. Para más información sobre este tema, véase Roulet (2011), quien analiza los casos de Carripilun, Puelmanc, Payllacura y Mariñan, entre otros.

21. Conformada por pehuenches e hispano-criollos de Chile y Mendoza, contra las fuerzas de los huilliches-ranqueles al mando de Llanquetur.

22. Copia del oficio de Arredondo a Sobremonte. Buenos Aires, 24 de diciembre de 1791. AGN, sala IX, División Colonia, Sección Gobierno. Legajo 24.2.2, Guerra y Marina (1792), Expediente $\mathrm{N}^{\circ} 19$.

23. Copia del oficio de Juan Morel a Amigorena. Villa de San Carlos, 14 de febrero de 1792. AGN, sala IX, División Colonia, Sección Gobierno. Legajo 24.2.2, Guerra y Marina (1792), Expediente $\mathrm{N}^{\circ} 19$.

24. De acuerdo a un cautivo escapado de las tolderías ranqueles en 1770, este cacique era uno de los principales de Mamuel Mapu junto a Llanquetur (Roulet, 2016).

25. Copia del oficio de Juan Morel a Amigorena. Villa de San Carlos, 14 de febrero de 1792. AGN, sala IX, División Colonia, Sección Gobierno. Legajo 24.2.2, Guerra y Marina (1792), Expediente $\mathrm{N}^{\circ} 19$. Probablemente se esté haciendo referencia al río Reñileuvú, un afluente del río Negro.

26. Copia del oficio de Amigorena a los Ministros de Real Hacienda. Mendoza, 16 de febrero de 1792. AGN, sala IX, División Colonia, Sección Gobierno. Legajo 24.2.2, Guerra y Marina (1792), Expediente $\mathrm{N}^{\circ} 19$. Oficio de Amigorena a Sobremonte. Mendoza, 18 de febrero de 1792 . AGN, sala IX, División Colonia, Sección Gobierno. Legajo 24.2.2, Guerra y Marina (1792), Expediente $\mathrm{N}^{\circ} 19$.

27. Solo mencionamos las prestaciones a las que accedieron los pehuenches y los hispano-criollos y que se vinculan con nuestra fuente bajo análisis. Para más información sobre los puntos acordados, véase Roulet (1999-2001).

28. Sobre el tema de la instalación del enclave pehuenche y la localización y corrimientos que sufren las tolderías de Roco (por ejemplo, tras la huida del cacique), véase Roulet (1999-2001). De acuerdo a dicha autora, en las cercanías del fuerte de San Carlos también estaban los pehuenches fronterizos al mando del cacique Carilef y el de los puelches fronterizos comandados por Bartolo Guenecal. Si bien los pehuenches fronterizos no fueron numerosos, sí fueron efectivos en colaborar en la pacificación de la frontera mendocina: protegieron los accesos a la ciudad de Mendoza; aseguraron el abasto de la sal proveniente de las salinas entre los ríos Atuel y Diamante y permitieron el avance de las estancias ganaderas hacia el sur (Roulet,1999-2001), No obstante, debieron asumir los costos humanos y materiales de la guerra de fronteras, además de la presión de tener que suscribir a un compromiso militar, que se tradujo en matanzas de otras parcialidades enemigas (Roulet, 2016).

29. En 1787, el mismísimo Currilipi sufrió amenazas de ataque huilliche. De acuerdo a lo que el cacique Roco le comunicó a Esquivel Aldao, ello se debió a que -según los huilliches- este cacique los había engañado diciendo que “...además de Ancan se habían muerto sus hermanos y demás pehuenches de Malalgue" (Roulet, 2016, p. 177).

30. Mientras que los pehuenches de Malargüe implementaron la estrategia de refugiarse en un improvisado corral (malal) obligando a sus enemigos a desgastarse atacando el baluarte (León Solís, 2001). 
31. Aunque este Parlamento debilitó coyunturalmente el monopolio que los caciques de Malargüe habían tenido por sobre las relaciones fronterizas de Mendoza y Chillán, posibilitó extender el espacio pacificado más de $500 \mathrm{~km}$ hacia el sur (León Solís, 2001).

32. Oficio de Amigorena a Sobremonte. Mendoza, 18 de febrero de 1792. AGN, sala IX, División Colonia, Sección Gobierno. Legajo 24.2.2, Guerra y Marina (1792), Expediente $N^{\circ} 19$.

33. Hacia marzo de 1778 Amigorena contabilizó: 15 compañías incompletas, 200 fusiles (con solo 30 útiles), 300 sables que no podían ser manejados por ser muy grandes, pesados, gruesos y de mal filo, y 500 lanzas más o menos utilizables (Comando General del Ejército, 1973, p. 18).

34. Oficio de Amigorena a Sobremonte. Mendoza, 18 de febrero de 1792. AGN, sala IX, División Colonia, Sección Gobierno. Legajo 24.2.2, Guerra y Marina (1792), Expediente $\mathrm{N}^{\circ} 19$.

35. Oficio de Amigorena a Sobremonte. Mendoza, 18 de febrero de 1792. AGN, sala IX, División Colonia, Sección Gobierno. Legajo 24.2.2, Guerra y Marina (1792), Expediente $\mathrm{N}^{\circ} 19$.

36. Este cargo hunde sus raíces en Chile y puede ser rastreado a la segunda mitad del siglo XVII. Sus funciones eran duales: mediaban entre españoles e indígenas y asesoraban a los líderes étnicos en sus tratos con las autoridades y protocolos en virtud de que conocían su idioma y sus costumbres. Para más información sobre este tema, véase León Solís (1982).

37. Oficio de Amigorena a Sobremonte. Mendoza, 18 de febrero de 1792. AGN, sala IX, División Colonia, Sección Gobierno. Legajo 24.2.2, Guerra y Marina (1792), Expediente $\mathrm{N}^{\circ} 19$.

38. Copia del Oficio de José Antonio Palacio a Sobremonte. Mendoza, 10 de febrero de 1792. AGN, sala IX, División Colonia, Sección Gobierno. Legajo 24.2.2, Guerra y Marina (1792), Expediente $\mathrm{N}^{\circ} 19$.

39. Copias de oficio de José Antonio de Palacio a José Francisco de Amigorena. Mendoza, 11 de febrero de 1792. AGN, sala IX, División Colonia, Sección Gobierno. Legajo 24.2.2, Guerra y Marina (1792), Expediente $\mathrm{N}^{\circ} 19$. Copia de la contestación de Amigorena a los Ministros de Real Hacienda. Mendoza, 15 de febrero de 1792. AGN, sala IX, División Colonia, Sección Gobierno. Legajo 24.2.2, Guerra y Marina (1792), Expediente $\mathrm{N}^{\circ} 19$.

40. Oficio de Sobremonte a Arredondo. Córdoba, 15 de marzo de 1792. AGN, sala IX, División Colonia, Sección Gobierno. Legajo 24.2.2, Guerra y Marina (1792), Expediente $\mathrm{N}^{\circ} 19$.

41. Oficio de Sobremonte a Arredondo. Córdoba, 15 de marzo de 1792. AGN, sala IX, División Colonia, Sección Gobierno. Legajo 24.2.2, Guerra y Marina (1792), Expediente $\mathrm{N}^{\circ} 19$.

42. Las fuerzas huilliches-ranqueles variaban y fluctuaban de acuerdo a las estaciones del año y la magnitud del botín pretendida en los ataques a los emplazamientos hispano-criollos (León Solís, 2001).

43. Imposibilidad de leer la finalización de la palabra por el encuadernado del expediente.

44. No se puede identificar cómo termina esta palabra por el encuadernado del expediente.

45. Palabras agregadas sobre el margen superior del renglón.

46. A continuación de la palabra 'papel' hay una suerte de sigla que no puede identificarse.

47. No se puede leer la totalidad de la palabra por el pliegue del encuadernado del documento.

\section{ABSTRACTS}

We present the transcription of some documents about the frontier of Mendoza that correspond to the period between December of 1791 and March of 1792. The file includes official communications and official communications copies, just as the respective replies. We can 
identify certain polyphonies in the communication between different subjects acting at the frontier of Mendoza.

These sources revolve around the confrontation between Pehuenches and Huilliches-Ranqueles, as well as Mendoza's aid to the first ones. We consider that they have ethnographic and historical value since they allow us to contribute to problems raised by other investigators such as the alliance between Hispanic-creoles and Pehuenches pointing out the services and compensations of each covenant group. Also, the issue of the changeable ethnic identities and the harnessing of the localization of certain tolderías of allied indigenous groups - "indios amigos"- as strips that protected the defensive and productive establishments of the Hispanic-creole. On the other hand, as a cross-cutting theme in the official communications, is the Hispanic-creole's concern about how that conflict may affect them directly or indirectly, increasing their expenses and forcing them to reconsider their border policy, that enabled us to state the difficult financial situation of the colonial administration of Mendoza, which encourages us to continue enquiring about that matter in future investigations, in order to shed more light on the decisions concerning border policy.

Presentamos la transcripción de algunos documentos relativos a la frontera de Mendoza que corresponden al período entre diciembre de 1791 y marzo de 1792. El expediente incluye oficios y copias de oficios, así como las respectivas contestaciones. De esta forma, podemos identificar ciertas polifonías en la comunicación entre diferentes actores de la frontera de Mendoza.

Estas fuentes giran en torno al enfrentamiento entre los pehuenches y los huilliches-ranqueles, así como al auxilio mendocino a los primeros. Consideramos que ellas tienen un gran valor etnográfico e histórico dado que nos permiten aportar a problemas planteados por otros investigadores tales como la alianza entre hispano-criollos y pehuenches, puntualizando las prestaciones y contraprestaciones de cada grupo pactante. También, la cuestión de las identidades étnicas cambiantes y el aprovechamiento de la localización de determinadas tolderías de grupos indígenas aliados - “indios amigos"- como franjas que protegieran los establecimientos defensivos y productivos hispano-criollos. Por otro lado, un tema transversal a las fuentes es la preocupación hispano-criolla sobre cómo ese conflicto podía afectarlos directa e indirectamente, acrecentando sus gastos y obligándolos a replantearse su política fronteriza. Ello nos permitió señalar la dificultosa situación financiera de la administración colonial en Mendoza, lo que nos alienta a seguir indagando sobre esa cuestión en investigaciones futuras, para así arrojar más luz sobre las decisiones tomadas en cuanto a la política fronteriza. ${ }^{1}$

INDEX

Keywords: Frontier, Mendoza, Pehuenches, Huilliches-Ranqueles

Palabras claves: Frontera, Mendoza, pehuenches, huilliches-ranqueles

\section{AUTHOR}

\section{LUCIANA FERNÁNDEZ}

Centro de Investigaciones Sociales-Consejo Nacional de Investigaciones Científicas y Técnicas Instituto de Desarrollo Económico y Social, Argentina

Correo electrónico: lucianafernandez1987@gmail.com 